\title{
SLIM1 Transcription Factor Promotes Sulfate Uptake and Distribution to Shoot, Along with Phytochelatin Accumulation, Under Cadmium Stress in Arabidopsis thaliana
}

\author{
Chisato Yamaguchi ${ }^{1,2}$, Soudthedlath Khamsalath ${ }^{1,3}$, Yuki Takimoto ${ }^{4}$, Akiko Suyama ${ }^{1,5}$, \\ Yuki Mori ${ }^{1}$, Naoko Ohkama-Ohtsu ${ }^{6,7}$ and Akiko Maruyama-Nakashita 1,4,*(D) \\ 1 Department of Bioscience and Biotechnology, Graduate School of Bioresource and Bioenvironmental \\ Sciences, Faculty of Agriculture, Kyushu University, 744 Motooka, Nishi-ku, Fukuoka 819-0395, Japan; \\ yamaguchic124@affrc.go.jp (C.Y.); soudthedlath.most@gmail.com (S.K.); aksuyama@nm.beppu-u.ac.jp (A.S.); \\ y-mori@agr.kyushu-u.ac.jp (Y.M.) \\ 2 NARO Tohoku Agricultural Research Center, 4 Akahira, Shimo-Kuriyagawa, Morioka 020-0198, Japan \\ 3 Ministry of Science and Technology, Biotechnology and Ecology Institute, Genetic Resources Division, \\ Don Teaw village, KM 14 office, Tha Ngon Road, Xaythany district, Vientiane 01170, Laos \\ 4 Faculty of Bioscience, Fukui Prefectural University, 4-1-1 Kenjojima, Matsuoka, Eiheiji-town, Fukui 910-1195, \\ Japan; YukiTakimoto@gmail.com \\ 5 Department of Food and Fermentation Sciences, Faculty of Food and Nutrition Sciences, Beppu University, \\ 82 Kita-Ishigaki, Beppu, Oita 874-8501, Japan \\ 6 Institute of Agriculture, Tokyo University of Agriculture and Technology, 3-5-8 Saiwai-cho, Fuchu-shi, \\ Tokyo 183-8509, Japan; nohtsu@cc.tuat.ac.jp \\ 7 Institute of Global Innovation Research, Tokyo University of Agriculture and Technology, 3-5-8 Saiwai-cho, \\ Fuchu-shi, Tokyo 183-8509, Japan \\ * Correspondence: amaru@agr.kyushu-u.ac.jp; Tel.: +81-92-802-4712
}

Received: 27 November 2019; Accepted: 25 January 2020; Published: 29 January 2020

\begin{abstract}
Sulfur (S) assimilation, which is initiated by sulfate uptake, generates cysteine, the substrate for glutathione (GSH) and phytochelatin (PC) synthesis. GSH and PC contribute to cadmium (Cd) detoxification by capturing it for sequestration. Although $\mathrm{Cd}$ exposure is known to induce the expression of S-assimilating enzyme genes, including sulfate transporters (SULTRs), mechanisms of their transcriptional regulation are not well understood. Transcription factor SLIM1 controls transcriptional changes during $S$ deficiency $(-S)$ in Arabidopsis thaliana. We examined the potential involvement of SLIM1 in inducing the $S$ assimilation pathway and PC accumulation. Cd treatment reduced the shoot fresh weight in the sulfur limitation1 (slim1) mutant but not in the parental line (1;2PGN). Cd-induced increases of sulfate uptake and SULTR1;2 expressions were diminished in the slim1 mutant, suggesting that SLIM1 is involved in inducing sulfate uptake during Cd exposure. The GSH and PC levels were lower in slim 1 than in the parental line, indicating that SLIM1 was required for increasing PC during Cd treatment. Hence, SLIM1 indirectly contributes to Cd tolerance of plants by inducing $-\mathrm{S}$ responses in the cell caused by depleting the GSH pool, which is consumed by enhanced PC synthesis and sequestration to the vacuole.
\end{abstract}

Keywords: Cadmium stress; Arabidopsis thaliana; sulfate transport; SLIM1 transcription factor; phytochelatin 


\section{Introduction}

Cadmium (Cd) is highly toxic but non-essential for living organisms [1-3]. It is released from natural and anthropogenic sources into the environment where it accumulates in the soil. Plants growing in Cd-contaminated soil typically absorb the heavy metal via cation transporters located on the root surface and facilitate its transport to aerial tissues [4-9]. Phytotoxic effects of $\mathrm{Cd}$ include growth inhibition, leaf chlorosis, and nutrient deficiencies $[3,9,10]$. However, plants have evolved multiple mechanisms to tolerate $\mathrm{Cd}$ exposure [10-14].

It has been demonstrated that $\mathrm{Cd}$ is chelated by low-molecular, sulfur (S)-containing compounds, such as glutathione (GSH) or phytochelatin (PC), and sequestrated into the vacuole as GSH-Cd or PC-Cd complexes, respectively $[5,10,15-17]$. Thus, plants can diminish the toxicity of $\mathrm{Cd}$ by lowering its cytosolic concentration $[11,15,16,18]$. GSH is a tri-peptide thiol synthesized from cysteine (Cys), glutamate (Glu), and glycine (Gly) by $\gamma$-glutamylcysteine synthetase (GSH1) and glutathione synthetase (GSH2). It contributes to Cd detoxification both as a scavenger of reactive oxygen species (ROS) and as a substrate of PC synthesis $[13,19]$. Phytochelatin synthase (PCS) synthesizes PC by sequentially adding $\gamma$-glutamylcysteine to GSH to generate PC oligomers of variable lengths with the general structure $(\gamma \text {-Glu-Cys })_{n}$ Gly $(n=2-11)$ [20]. PC levels and PCS activity are highly enhanced upon Cd exposure, whereas the transcript levels of PCS genes, PCS1 and PCS2 in Arabidopsis, remain relatively constant $[21,22]$. PCS is activated by binding to heavy metals, resulting in the quick initiation of PC synthesis upon heavy metal exposure [23,24]. The importance of GSH and PC for Cd tolerance is also indicated by the observation that certain mutations in either the PCS1 or GSH1 gene are associated with the Cd-sensitive phenotypes of the corresponding cad1 or cad2 mutants [25-27].

Cd exposure-induced synthesis of GSH and PC stimulates $\mathrm{S}$ assimilation by Cys, a major substrate for GSH synthesis [28-31]. Recent studies reported the close relation between sulfur availability and increased plant tolerance to Cd stress [32-36]. S assimilation in plants starts with the uptake of sulfate by the rhizosphere via sulfate transporters (SULTR) [30,31,37]. Sulfate is absorbed by the root cells and translocated to the plastids, where it is reduced to sulfide by several enzymatic reactions, and assimilated into Cys [28-31]. The SULTR family in Arabidopsis contains 12 members, which can be divided into four distinct functional groups $[30,31,37]$. Two high-affinity group 1 SULTR proteins, SULTR1;1 and SULTR1;2, facilitate the uptake of sulfate into roots [29,30,36,37]. Group 2 SULTR proteins are low-affinity sulfate transporters that contribute to the sulfate transport through vascular tissues [30,31,37-39]. Group 3 SULTR proteins reside in the plastid membrane to ensure the sulfate influx into the plastids [40-42]. Group 4 SULTR proteins are responsible for the efflux of sulfate from vacuoles [43]. Transcript levels of the genes involved in S assimilation and GSH synthesis, including SULTR, GSH1, and GSH2, are increased in response to Cd stress, resulting in the upregulation of enzymatic activities [22,44-49]. Indeed, Cd-induced sulfate uptake mainly depends on the elevated expression of SULTR1;2 [50,51]. Cd exposure causes increased sulfate distribution to the shoots, along with an increased sulfate concentration in xylem sap and the upregulated expression of the SULTR genes involved in root-to-shoot sulfate transport, such as SULTR2;1 and SULTR3;5 [38-40,51].

There are many similarities between plant responses to $\mathrm{Cd}$ exposure and $\mathrm{S}$ deficiency $(-\mathrm{S})$; both stimulate sulfate uptake, sulfate translocation to shoots, and sulfate reduction, along with its assimilation into Cys [22,52-55]. In -S responses, Sulfur LIMitation1 (SLIM1), an ethylene insensitive 3-like (EIL) family transcription factor, plays a central role in inducing the transcriptional responses [53]. SLIM1 activates sulfate acquisition for S assimilation by upregulating SULTR1;1, SULTR1;2, SULTR4;1, and SULTR4;2 in response to $-S$ conditions [53]. However, it is still unclear how much the $-S$-induced changes in the transcriptome contribute to the $\mathrm{Cd}$-induced responses and the $\mathrm{Cd}$ tolerance in plants. In this study, we investigated the involvement of SLIM1 in plant responses to Cd exposure and its significance in $\mathrm{Cd}$ tolerance by comparing the $\mathrm{Cd}$-responsive phenotypes of the slim 1 mutant

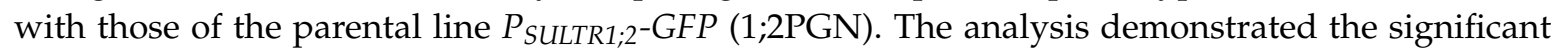
contribution of SLIM1 to the Cd-responsive induction of sulfate uptake, sulfate distribution to shoots, and PC accumulation. 


\section{Results}

\subsection{The slim1 Mutant Was More Sensitive to Cd and Accumulated Less Cd Than the Parental Line 1;2PGN}

To define the contribution of the SLIM1 transcription factor to plant tolerance for Cd, we compared the effects of $\mathrm{Cd}$ treatment on growth and $\mathrm{Cd}$ accumulation in a slim1 mutant, slim1-2, with those in the parental line, 1;2PGN (Figure 1a). 1;2PGN is a transgenic line harboring a fusion gene construct consisting of the 2,160 bp 5'-upstream region of SULTR1;2 and the coding region of GFP; this line accumulates GFP in response to $-S$ [55].

When plants were grown without $\mathrm{Cd}$, the fresh weights of shoots and roots of slim1-2 and 1;2PGN plants were similar. Cd exposure did not affect the root fresh weight in slim1-2 or 1;2PGN. In contrast, the shoot fresh weight of slim1-2 was decreased by Cd treatment, whereas that of 1;2PGN was not affected (Figure 1a). Cd tolerance rates described as Cd20/Cd0 rate of shoots fresh weight were $100 \%$ and $72 \%$ in $1 ; 2$ PGN and slim1-2, respectively.

Then Cd levels in roots and shoots of the plants exposed to $20 \mu \mathrm{MCdCl}_{2}$ were analyzed (Figure $1 \mathrm{~b}$ ). $\mathrm{Cd}$ levels in the root tissues were lower in slim1-2 than in 1;2PGN, whereas those in the shoots did not vary between the genotypes, as observed in the knockout lines of SULTR1;2 [51]. These data indicated that SLIM1 contributed to Cd tolerance and accumulation in plants.
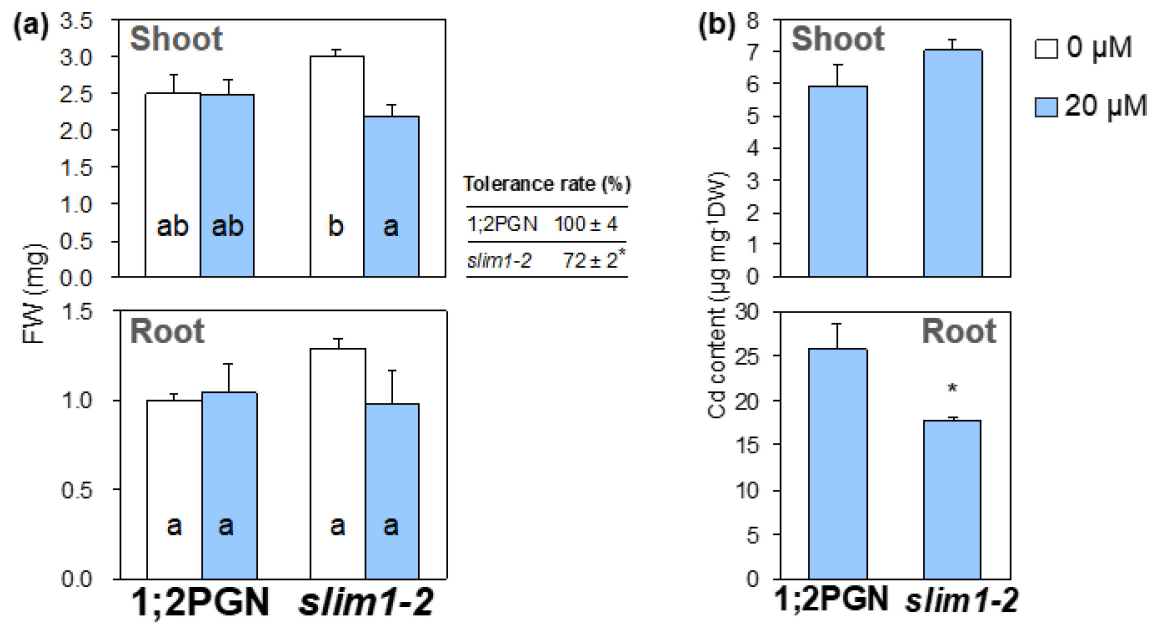

Figure 1. Effects of $\mathrm{Cd}$ treatment on plant growth and $\mathrm{Cd}$ accumulation in 1;2PGN and slim1-2. (a) Fresh weight of shoots (upper graph) and roots (lower graph). The Cd tolerance rate (\%) was calculated by dividing the shoot fresh weights of the Cd-treated plants by those of the control plants. (b) Cd content in shoots (upper graph) and roots (lower graph). Also, 1;2PGN and slim1-2 were grown for 10 days on MGRL agar medium containing 0 (white bars) or 20 (light blue bars) $\mu \mathrm{MCdCl}_{2}$. The average values are indicated with error bars denoting SEM $(n=4)$. Different letters indicate significant differences between experimental groups (Tukey-Kramer test; $p<0.05$ ). Asterisks indicate significant differences between 1;2PGN and slim1-2 (Student's $t$-test; ${ }^{*} p<0.05$ ).

2.2. Cd-Induced Increases of Sulfate Uptake, Sulfate Transport to Shoots, and Sulfate Content in Shoots Were Diminished in slim1-2

Since slim1-2 was more susceptible to Cd treatment than 1;2PGN, we further compared the effects of $\mathrm{Cd}$ treatment on sulfate uptake, transport to shoots, and sulfate accumulation between slim1-2 and 1;2PGN (Figure 2).

$\mathrm{Cd}$ treatment enhanced sulfate uptake and distribution to shoots in 1;2PGN (Figure 2a). The corresponding increases were not significant in slim1-2, and the rates of increase were below those in 1;2PGN. Specifically, sulfate uptake was increased 1.6-fold and 1.4-fold in 1;2PGN and slim1-2, and sulfate distribution to shoots was increased 6.8-fold and 3.3-fold in 1;2PGN and slim1-2, respectively. 
$\mathrm{Cd}$ exposure had a similar effect on the sulfate levels in 1;2PGN and slim1-2 (Figure 2b). When plants were grown without $\mathrm{Cd}$, sulfate levels in shoots and roots did not differ between 1;2PGN and slim1-2. In response to Cd exposure, sulfate levels in shoots were increased 1.70-fold and 1.57-fold in 1;2PGN and slim1-2, respectively, whereas the root sulfate levels were not affected by Cd exposure in 1;2PGN and slim1-2 (Figure 2b). These results indicated that sulfate uptake and distribution to shoots under $\mathrm{Cd}$ treatment were lower in slim1-2 than in 1;2PGN.
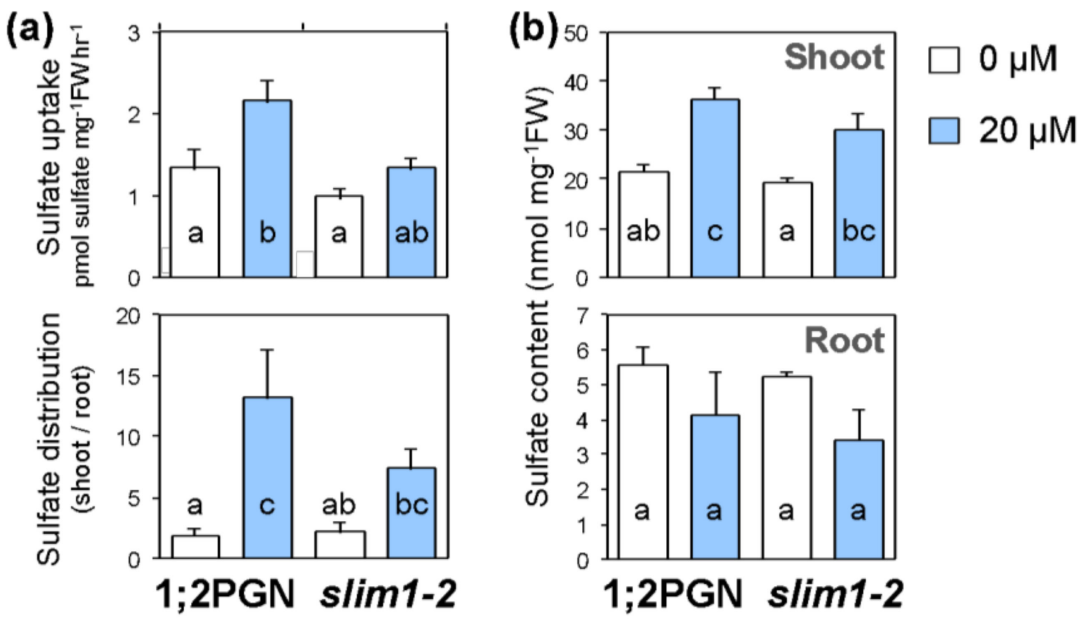

Figure 2. Effects of $\mathrm{Cd}$ treatment on sulfate uptake, distribution, and content in 1;2PGN and slim1-2 plants. (a) The absolute values of $\left[{ }^{35} \mathrm{~S}\right]$ sulfate uptake rates (upper graph) and sulfate distribution shown as the shoot/root ratio of $\left[{ }^{35} \mathrm{~S}\right]$ sulfate accumulations (lower graph). (b) Sulfate content in shoots (upper graph) and roots (lower graph) of 1;2PGN and slim1-2. Plants were grown for 10 days on MGRL agar medium containing 0 (white bars) or 20 (light blue bars) $\mu \mathrm{M} \mathrm{CdCl}_{2}$. Sulfate content was determined by ion chromatography. The average values are indicated with error bars denoting SEM ( $n=4-7$ in a, $n=4$ in b). Different letters indicate significant differences among experimental groups (Tukey-Kramer test; $p<0.05$ ).

\subsection{Cd-Inducible Expression of SULTR1;2 Was Moderated in slim1-2}

Sulfate uptake from roots is facilitated by SULTR1;1 and SULTR1;2, whose transcript levels are strongly increased by $-S$ in a SLIM1-dependent manner [53]. Although SULTR1;2 was defined as the main contributor to Cd-induced sulfate uptake in Arabidopsis [51], the involvement of SLIM1 in this induction process has not been reported. The transcript levels of two low-affinity sulfate transporter genes, SULTR2;1 and SULTR3;5, which are known to be involved in the root-to-shoot sulfate transport [38-40], were increased by $C d$ exposure and $-S$ [22,38-40,54,56], but their $-S$ responses did not depend on SLIM1 [53].

To examine whether SLIM1 mediates the increase in sulfate uptake accompanied by transcript accumulation of SULTR1;1 and SULTR1;2 or in root-to-shoot transport of sulfate during Cd exposure, transcript levels of SULTR1;1, SULTR1;2, SULTR2;1, and SULTR3;5 were analyzed in 1;2PGN and slim1-2 roots (Figure 3).

Cd treatment did not affect the transcript levels of SULTR1;1 and SULTR1;2 in 1;2PGN or slim1-2 roots. However, SULTR1;2 expression tended to be stimulated by Cd treatment in 1;2PGN roots but not in slim1-2 roots (Figure 3) with p values of 0.10 and 0.64 , respectively, which were calculated with Student's t-test, comparing the 0 and $20 \mu \mathrm{M} \mathrm{CdCl}_{2}$ treatment groups. These results suggested that SLIM1 is required for inducing SULTR1;2 transcription in roots during Cd exposure.

SULTR2; 1 is suggested to contribute to the increased root-to-shoot sulfate transport during Cd exposure [50], and the co-expression of SULTR3;5 can stimulate the activity of SULTR2;1 [39]. $\mathrm{Cd}$ treatment tended to increase SULTR2;1 expression in 1;2PGN, and the increase was significant in slim1-2 (Figure 3), probably because the transcript levels of SULTR2;1 in shoots is decreased by 
microRNA395 which expression is induced by -S in SLIM1-dependent manner [56]. The SULTR3;5 transcript level was not affected by Cd treatment or SLIM1 impairment (Figure 3).
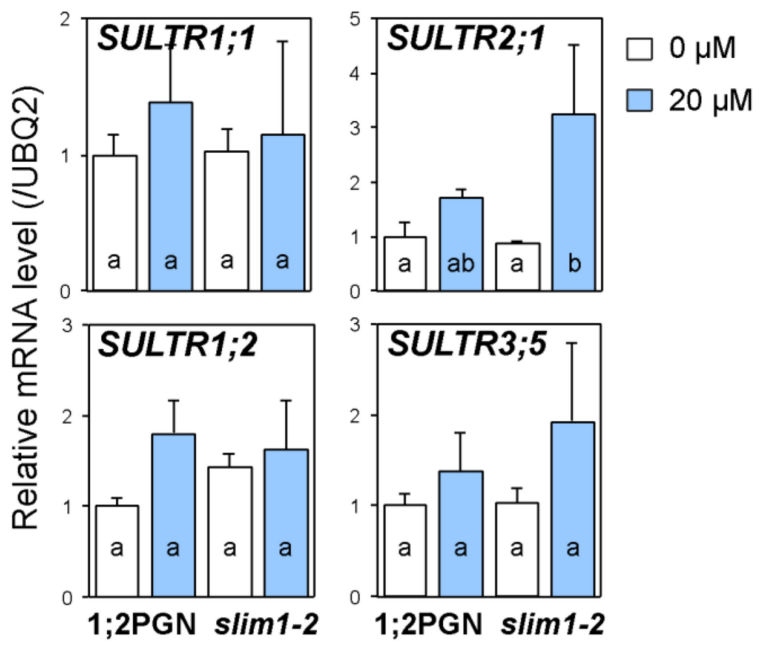

Figure 3. Effects of Cd treatment on transcript levels of SULTRs in 1;2PGN and slim1-2 roots. 1;2PGN and slim1-2 were grown for 10 days on MGRL agar medium containing 0 (white bars) or 20 (light blue bars) $\mu \mathrm{M} \mathrm{CdCl}$. Transcript levels of SULTRs in roots were determined by quantitative real-time PCR (qRT-PCR). The average values are indicated with error bars denoting SEM $(n=3-4)$. Different letters indicate significant differences among experimental groups (Tukey-Kramer test; $p<0.05$ ).

\subsection{Accumulation of GSH and PC Was Diminished in slim1-2}

We measured the total content of S, Cys, GSH, and PC in 1;2PGN and slim1-2, to determine the contribution of SLIM1 to the increased thiol accumulation during Cd exposure (Figure 4). When plants were grown without $\mathrm{Cd}$, the total $\mathrm{S}$ content in slim1-2 shoots was lower than that in 1;2PGN shoots; however, under $\mathrm{Cd}$ exposure, it was increased to the same level of that in 1;2PGN shoots. Cd treatment caused an increase in the root Cys content in slim1-2. The GSH content in the shoots was lower in slim1-2 than in 1;2PGN under both control and Cd-treated conditions, whereas the root GSH content was similar between control and Cd-treated conditions in 1;2PGN and slim1-2.
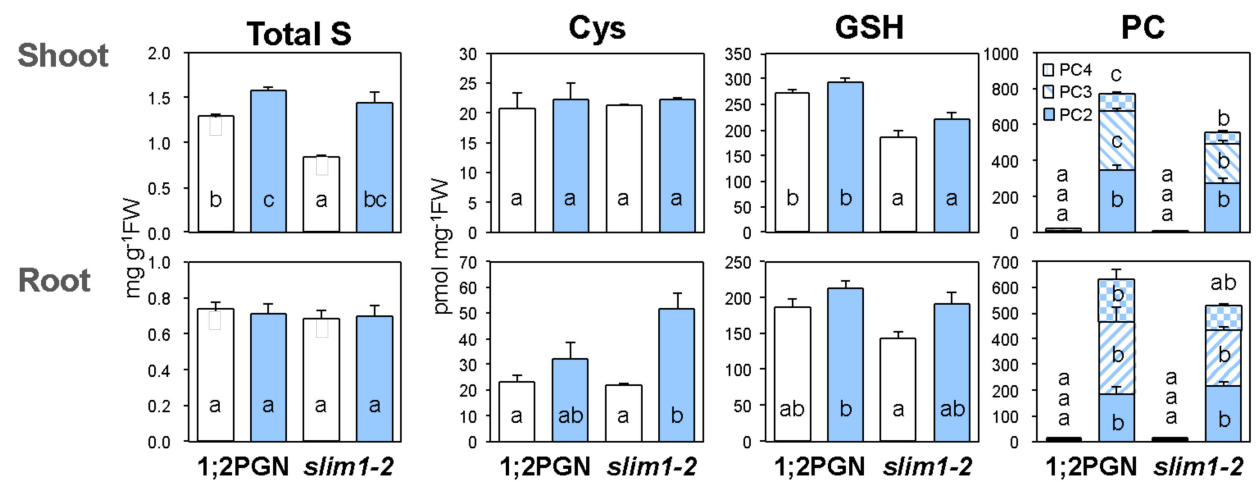

Figure 4. Effects of $\mathrm{Cd}$ treatment on the total content of $\mathrm{S}, \mathrm{Cys}, \mathrm{GSH}$, and PC in 1;2PGN and slim1-2. 1;2PGN and slim1-2 were grown for 10 days on MGRL agar medium containing 0 (white bars) or 20 (light blue bars) $\mu \mathrm{M} \mathrm{CdCl}_{2}$. Shoot and root tissues of 1;2PGN and slim1-2 were used as samples. Total S content was analyzed by ICP-MS. Contents of Cys, GSH, and PCs were analyzed using a HPLC-fluorescence detection system after labeling the thiol bases with monobromobimane. Cys: Cysteine, GSH: Glutathione, PC: Phytochelatin. The average values are indicated with error bars denoting SEM $(n=3-4)$. Different letters indicate significant differences among experimental groups (Tukey-Kramer test; $p<0.05)$. 
PCs were barely accumulated in shoot and root tissues of 1;2PGN and slim1-2 under control conditions. Upon Cd exposure, PC levels in both root and shoot tissues of 1;2PGN and slim1-2 were markedly increased. However, the PC3 and PC4 levels in shoots were significantly lower in slim1-2 than in 1;2PGN. Less PC3 and PC4 in the slim1-2 shoots, compared with that in the 1;2PGN shoots, suggested the involvement of SLIM1 in the increase of PC accumulation during Cd exposure.

\subsection{Cd Treatment and-S Additively Increased SULTR1;2 Expression and Sulfate Uptake, which Depended on SLIM1}

Cd-induced contributions of SLIM1 to the increase in sulfate uptake and the increase in PC levels suggested that the response to $C d$ exposure is partly mediated through $-S$ responses mediated by SLIM1. To demonstrate the involvement of $-S$ in the responses to Cd, SULTR1;2 expression was analyzed in 1;2PGN and two allelic mutants of SLIM1, slim1-1 and slim1-2, under Cd exposure combined with $-\mathrm{S}$ (Figure 5).

(a)

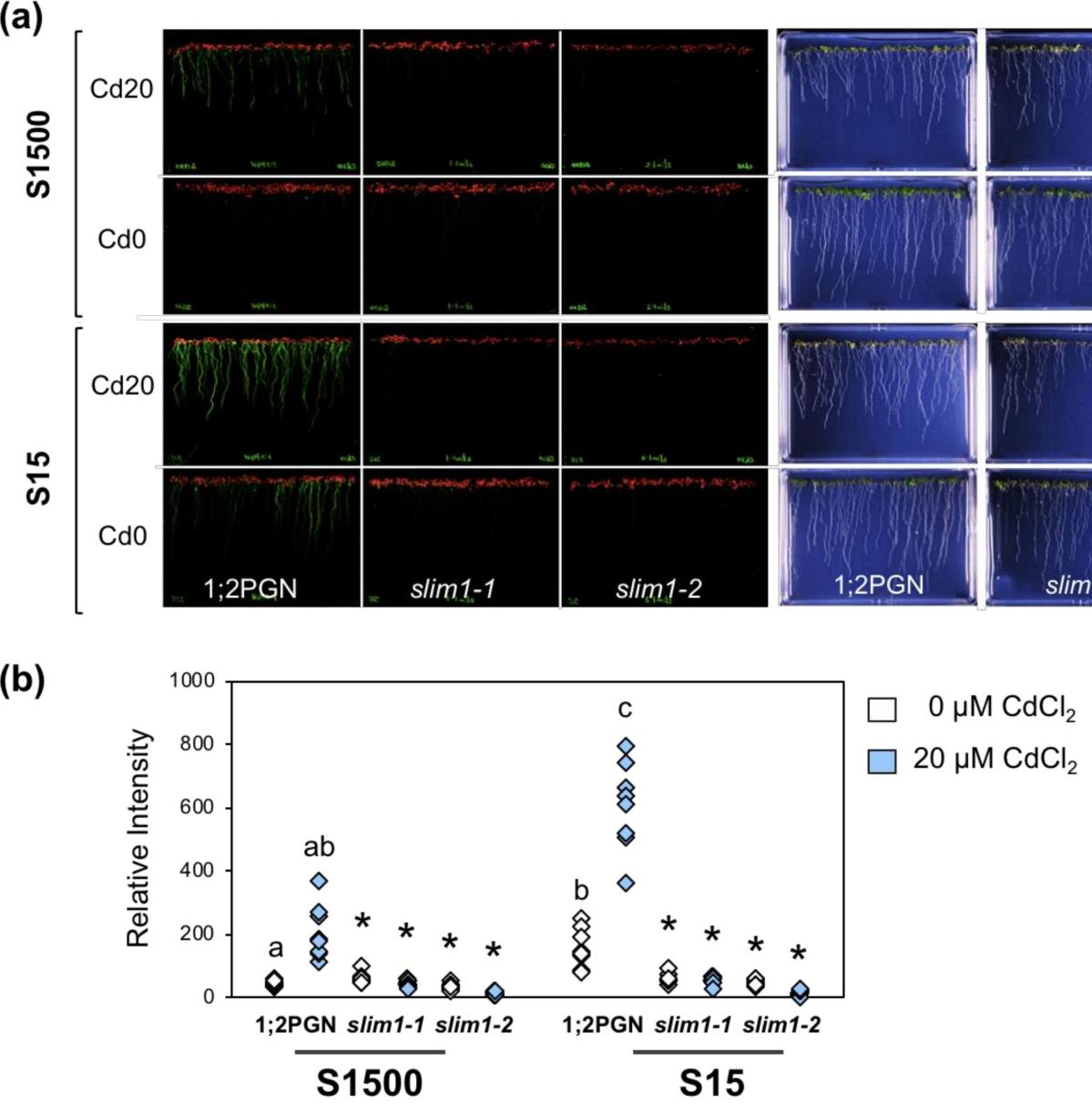

Figure 5. Effects of Cd treatment and -S on GFP and SULTR1;2 levels in 1;2PGN and slim1-2 plants. 1;2PGN, slim1-1 and slim1-2 seedlings were grown for 10 days on MGRL agar medium supplemented with 1500 or $15 \mu \mathrm{M}$ sulfate (S1500 or S15, respectively), which contained 0 or $20 \mu \mathrm{M} \mathrm{CdCl}_{2}$. (a) GFP

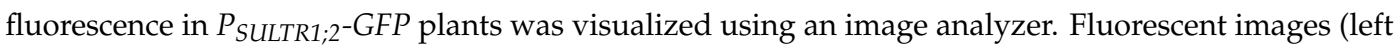
panels) and bright field images (right panels) are presented. (b) Relative GFP fluorescent intensities in (a) were processed by ImageQuant TL. The fluorescence intensities of plant roots grown on the agar medium containing 0 (white diamonds) or 20 (light blue diamonds) $\mu \mathrm{MCdCl}_{2}$ are displayed $(n=6)$. Different letters indicate significant differences between treatments in 1;2PGN (Tukey-Kramer test; $p<0.05)$. Asterisks indicate significant differences between 1;2PGN and slim 1 mutants (Student's $t$-test; $* p<0.05)$. 
Plants were grown on agar medium supplemented with 1500 or $15 \mu \mathrm{M}$ sulfate with or without $20 \mu \mathrm{M} \mathrm{CdCl}_{2}$, and the GFP fluorescence derived from a fusion gene construct, $P_{\text {SULTR } 12-G F P}$, was visualized and quantified in roots (Figure 5a,b). GFP signals in 1;2PGN roots were increased by reducing the sulfate levels in the medium, whereas those in slim1-1 and slim1-2 were not increased as reported previously [53]. Cd treatment increased GFP fluorescence in 1;2PGN roots in the presence of sulfate at any concentration, which also did not occur in the slim 1 mutants.

To assess whether the GFP levels observed in 1;2PGN and slim 1 mutants were associated with the SULTR1;2 expression and sulfate uptake, we examined the transcript levels of SULTR1;2, sulfate uptake, and the plant growth in 1;2PGN and slim 1 mutants under $-\mathrm{S}$ combined with $\mathrm{Cd}$ treatment (Figure 6a). The effects of Cd treatment and $-S$ on the SULTR1;2 transcript level and the GFP fluorescence were similar in the 1;2PGN and slim1 mutants (Figure 5), which was consistent with the results presented in Figure 2.
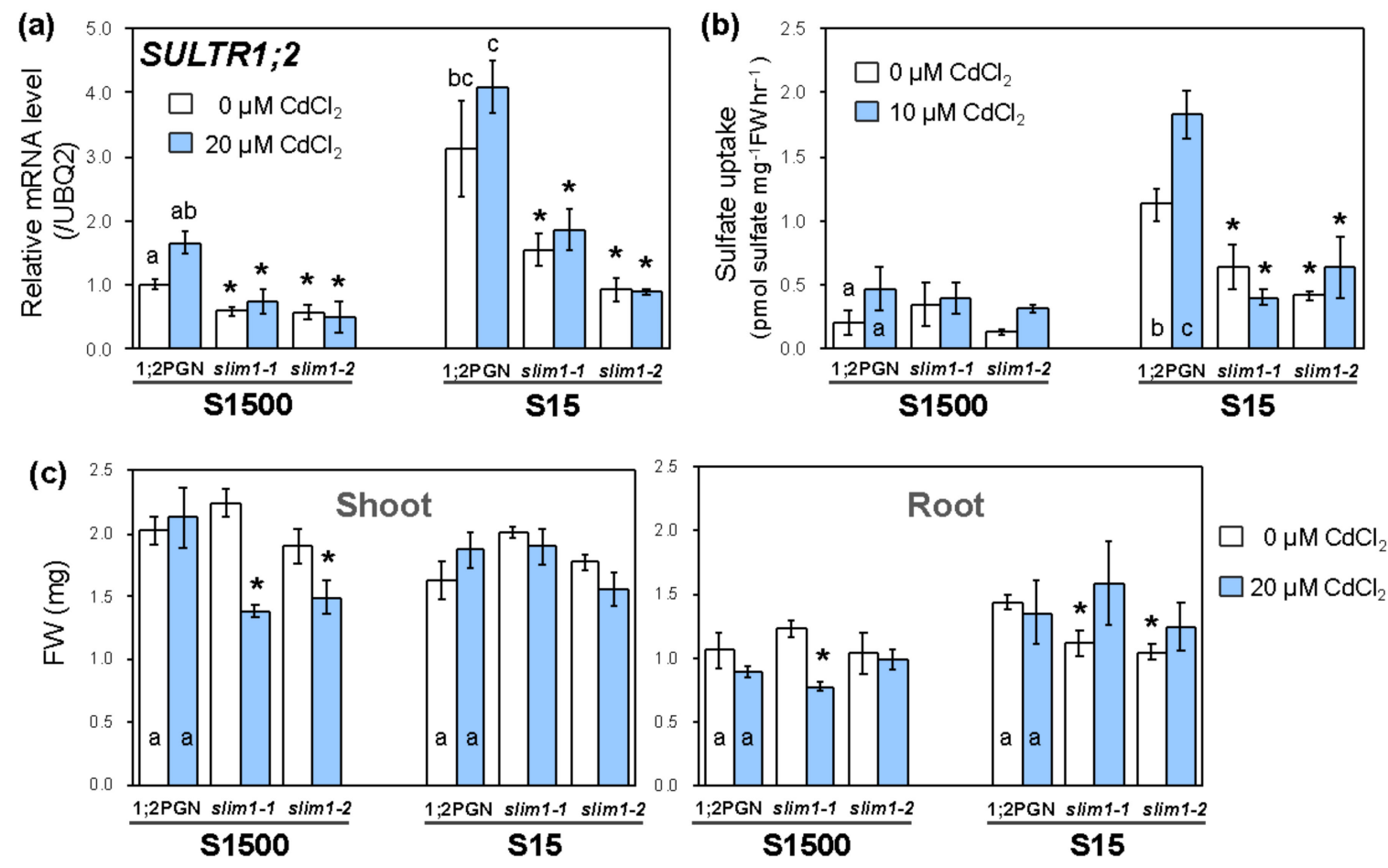

Figure 6. Effects of Cd treatment and -S on SULTR1;2 levels, sulfate uptake activity, and plant growth in 1;2PGN and $\operatorname{sim} 1$ plants. 1;2PGN and slim1 seedlings were grown for 10 days on MGRL agar medium supplemented with 1500 or $15 \mu \mathrm{M}$ sulfate (S1500 or S15, respectively), which contained 0 (white bars) or 10/20 (light blue bars) $\mu \mathrm{M} \mathrm{CdCl}_{2}$. (a) Transcript levels of SULTR1;2 in roots were determined by qRT-PCR. The average values are indicated with error bars denoting SEM $(n=2-4)$. Different letters indicate significant differences between treatments in 1;2PGN (Tukey-Kramer test; $p<0.05$ ). (b) The absolute values of $\left[{ }^{35} \mathrm{~S}\right]$ sulfate uptake rates are presented as averages with error bars denoting SEM $(n=5-6)$. Different letters indicate significant differences between treatments in 1;2PGN (Tukey-Kramer test; $p<0.05$ ). Asterisks indicate significant differences between 1;2PGN and slim1 mutants (Student's $t$-test; ${ }^{*} p<0.05$ ). (c) Fresh weight of shoots (left graph) and roots (right graph) per plant are presented as averages with error bars denoting SEM $(n=3-4)$. Different letters indicate significant differences between treatments in 1;2PGN (Tukey-Kramer test; $p<0.05$ ). Asterisks indicate significant differences among 1;2PGN and slim1 mutants in the same treatment (Student's $t$-test; ${ }^{*} p<0.05$ ).

The Cd treatment effect on sulfate uptake activity was consistent with that on SULTR1;2 expression (Figure $6 \mathrm{~b}$ ). Under $+S$, sulfate uptake activity in 1;2PGN was not significant but tended to be increased by $\mathrm{Cd}$ treatment. Sulfate uptake activity in 1;2PGN was increased by $-\mathrm{S}$ and enhanced by $\mathrm{Cd}$ treatment, whereas that in the slim1 mutants was not increased by $-\mathrm{S}$ and/or $\mathrm{Cd}$ treatment. 
Fresh weights of shoot and root tissues of 1;2PGN were not affected by $-\mathrm{S}$ and $\mathrm{Cd}$ treatment (Figure $6 \mathrm{c}$ ). The fresh weights of $\operatorname{sim} 1$ shoots were lower than those of 1:2PGN when plants were grown with $\mathrm{CdCl}_{2}$, corroborating our results shown in Figure 1a. Root fresh weights of slim1-1 and slim1-2 were lower than those of 1:2PGN when plants were grown under $-\mathrm{S}$, whereas they were similar to those of 1:2PGN when plants were grown with $\mathrm{Cd}$.

\subsection{SLIM1 Increases PC Levels in Response to Cd Treatment Even in Combination with-S}

Because SULTR1;2 expression and sulfate uptake were additively stimulated by $-\mathrm{S}$ and $\mathrm{Cd}$ treatment, and these stimulations were diminished in $\operatorname{sim} 1$ mutants, we examined the thiol content in 1;2PGN and slim1 mutants under $-\mathrm{S}$ combined with $\mathrm{Cd}$ treatment (Figure 7). The Cys content in $1 ; 2 \mathrm{PGN}$ shoots was not affected by $\mathrm{Cd}$ treatment but decreased by $-\mathrm{S}$, whereas that in 1;2PGN roots was increased by $\mathrm{Cd}$ treatment and not affected by $-\mathrm{S}$. The $\mathrm{Cd}$-induced increase of the Cys content in roots was more extensive under $-S$ than under $+S$. The Cys content in slim1-1 shoots was lower than that in 1;2PGN under $+\mathrm{S}$ exposed to $\mathrm{Cd}$. Roots of slim1 mutants accumulated more $C y s$ under $-\mathrm{S}$ as compared to that under $+S$, but the Cys content did not differ between $-S$ and $+S$ when treated with Cd.

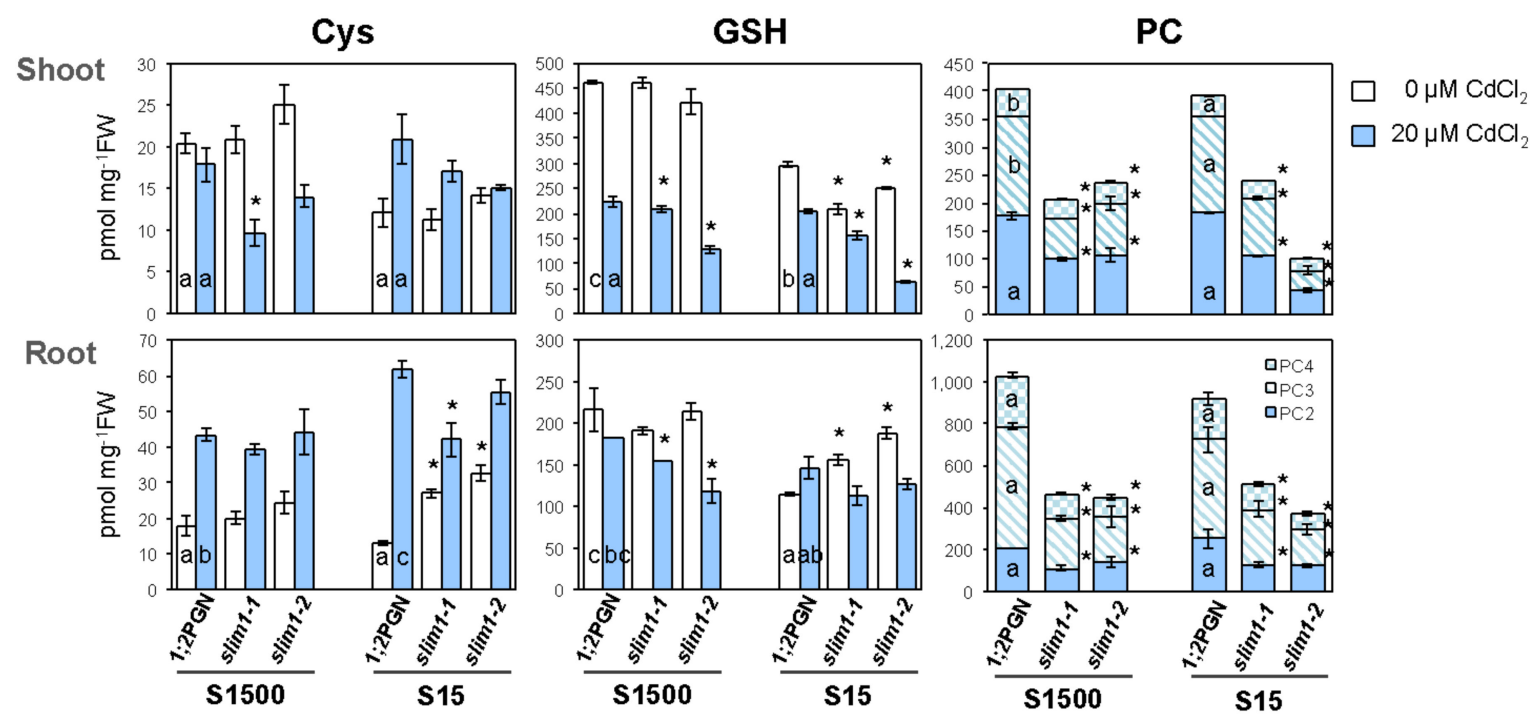

Figure 7. Effects of Cd treatment and -S on the content of Cys, GSH and PCs in 1;2PGN and slim1 plants. 1;2PGN, slim1-1, and slim1-2 seedlings were grown for 10 days on MGRL agar medium supplemented with 1500 or $15 \mu \mathrm{M}$ sulfate (S1500 and S15) and containing 0 (white bars) or 20 (light blue bars) $\mu \mathrm{M}$ $\mathrm{CdCl}_{2}$. Content of Cys, GSH, and PCs was analyzed by HPLC-fluorescent detection after labeling the thiol bases with monobromobimane. Cys: Cysteine, GSH: Glutathione, PC: Phytochelatin. The average values are indicated with error bars denoting SEM $(n=3-4)$. Different letters indicate significant differences between treatments in 1;2PGN (Tukey-Kramer test; $p<0.05$ ). Asterisks indicate significant differences among 1;2PGN and $\operatorname{slim} 1$ mutants using the same treatment (Student's $t$-test; ${ }^{*} p<0.05$ ).

The GSH content of 1;2PGN shoots was decreased by $-\mathrm{S}$ and $\mathrm{Cd}$ treatment, but it was similar under $+\mathrm{S}$ and $-\mathrm{S}$ when plants were exposed to $\mathrm{Cd}$. In slim 1 mutants, the GSH content in shoots was less than that in 1;2PGN when plants were grown under $-\mathrm{S}$ and/or $\mathrm{Cd}$ treatment. However, in 1;2PGN roots, the GSH content was not affected by Cd treatment but decreased by $-\mathrm{S}$. The GSH content in slim1 roots was lower than that in 1;2PGN when treated with $C d$ under $+S$, similar to that in shoots. Under $-\mathrm{S}$, slim1 roots accumulated more GSH than 1:2PGN roots did, but they had similar GSH levels when exposed to $C d$.

The increase in PC accumulation by $\mathrm{Cd}$ treatment was moderated in slim 1 mutants under both $\mathrm{S}$ conditions (Figure 7). PC was not detected in either 1;2PGN or slim1 mutants without Cd exposure 
(data not shown). In 1;2PGN, the PC content in roots did not vary between $+S$ and $-S$ during $C d$ treatment, but the PC3 and PC4 levels in shoots were significantly decreased under $-\mathrm{S}$. Upon Cd exposure, the PC content was much lower in slim1 mutants than in 1:2PGN under $+S$ or $-S$ in both roots and shoots. These results suggested that SLIM1 contributed to the accumulation of PC under $-S$ when treated with Cd.

\section{Discussion}

It is well documented that $\mathrm{Cd}$ induces PC synthesis and accumulation and enhances sulfate uptake and translocation to shoots in plants [3,9,10,12-15,20,25-27,46,47,51,57]. However, although the expression of genes involved in sulfate uptake and translocation was enhanced under both $-\mathrm{S}$ and Cd treatment [38,50,58-60], the contribution of -S-induced responses to the Cd-induced responses was not examined. Here we demonstrated the contribution of SLIM1, a central transcription factor coordinating $-S$ responses, to the increased sulfate uptake, sulfate distribution to shoots, and PC accumulation in response to $\mathrm{Cd}$ treatment based on the comparison between slim 1 mutants and its parental line 1;2PGN.

Sulfate uptake from roots is facilitated by SULTR1;1 and SULTR1;2, whose transcript levels are highly increased by $-S$ in a SLIM1-dependent manner [50,53,58-65]. The Cd-induced increase of sulfate uptake was suppressed in slim1 mutants (Figure 2a, Figure 6b), and SULTR1;2 expression tended to be increased in 1;2PGN but not in slim1 plants under Cd treatment (Figure 3, Figure 5, Figure 6a). These data indicated that SLIM1 contributed to the increased sulfate uptake by stimulating SULTR1;2 expression under $\mathrm{Cd}$ treatment.

$\mathrm{Cd}$ treatment increases sulfate distribution to shoots by stimulating root-to-shoot sulfate transport [51], which probably stimulates the S assimilation by transporting more sulfate to shoots, the main site of $\mathrm{S}$ assimilation. The sulfate distribution to shoots and the sulfate content in shoots were increased by $\mathrm{Cd}$ treatment in both 1;2PGN and slim1-2, but the rate of increase was lower in slim1-2 than that in 1;2PGN (Figure 2), indicating the involvement of SLIM1 in the increased sulfate distribution to shoots under Cd treatment. However, the induction rates of both SULTR2;1 and SULTR3;5 transcripts by Cd exposure were similar between 1;2PGN and slim1-2 (Figure 3), suggesting the existence of other mechanisms to increase sulfate distribution to shoots beside that coordinated by these SULTRs.

In addition, Cd-induced accumulation of PC was reduced in slim1 plants together with a lower GSH level in slim1 mutants (Figure 4, Figure 7), indicating a SLIM1 requirement for PC synthesis and accumulation induced by $\mathrm{Cd}$ exposure. The PC shortage in slim 1 mutants probably reduced the chelation of $\mathrm{Cd}$, which resulted in the reduction of shoot fresh weight during $\mathrm{Cd}$ exposure (Figure 1a, Figure 6c). Inadequate sulfate uptake in slim1 mutants should affect PC accumulation through the insufficient supply of Cys for PC synthesis, as observed in the disruption lines of SULTR1;2 and SULTR1;1 [51,64]. Thus, during Cd exposure in plants, SLIM1 is responsible for the increased uptake of sulfate, sulfate distribution to shoots, and PC accumulation in plants.

Although the involvement of SLIM1 in the regulation of S metabolism during Cd exposure has been demonstrated, increases of sulfate, thiols, and total S levels under $\mathrm{Cd}$ treatment were different from the situation of slim1 mutants grown under $-\mathrm{S}$ in which Cys and GSH levels were approximately $50 \%$ and $30 \%$ of those grown under S-sufficient conditions, respectively (Figure 2, Figure 4, Figure 7, Figure 8) [51,53]. It is plausible that cytosolic GSH and PC pools can be depleted during Cd treatment because of the sequestration of Cd-GSH and Cd-PC into vacuoles (Figure 8) [66,67], which may elevate the $S$ demand despite the increase of the total $S$ and thiol content (Figure 4). This hypothesis is supported by the observations that providing external Cys or GSH suppresses the expression of S-assimilatory genes, including SULTR1;1 and SULTR1;2 [55,66,68], and that the expression of SULTR1;2 is stimulated by the demand for $S$ [50]. How plants recognize the $S$ status has been a long-debated issue. Studies have identified the roles of various proteins and metabolites, e.g., SULTR1;2, a transporter/receptor sensing the sulfate concentration $[69,70], O$-acetyl-L-serine, a precursor of Cys synthesis that is sensed as the $-S$ indicator [71-73], and a toll-like receptor that integrates the $S$ demand and the demand for 
carbon and nitrogen [74]. Our study revealed the role of the cytosolic GSH level as an indicator of the S status sensed by plants.

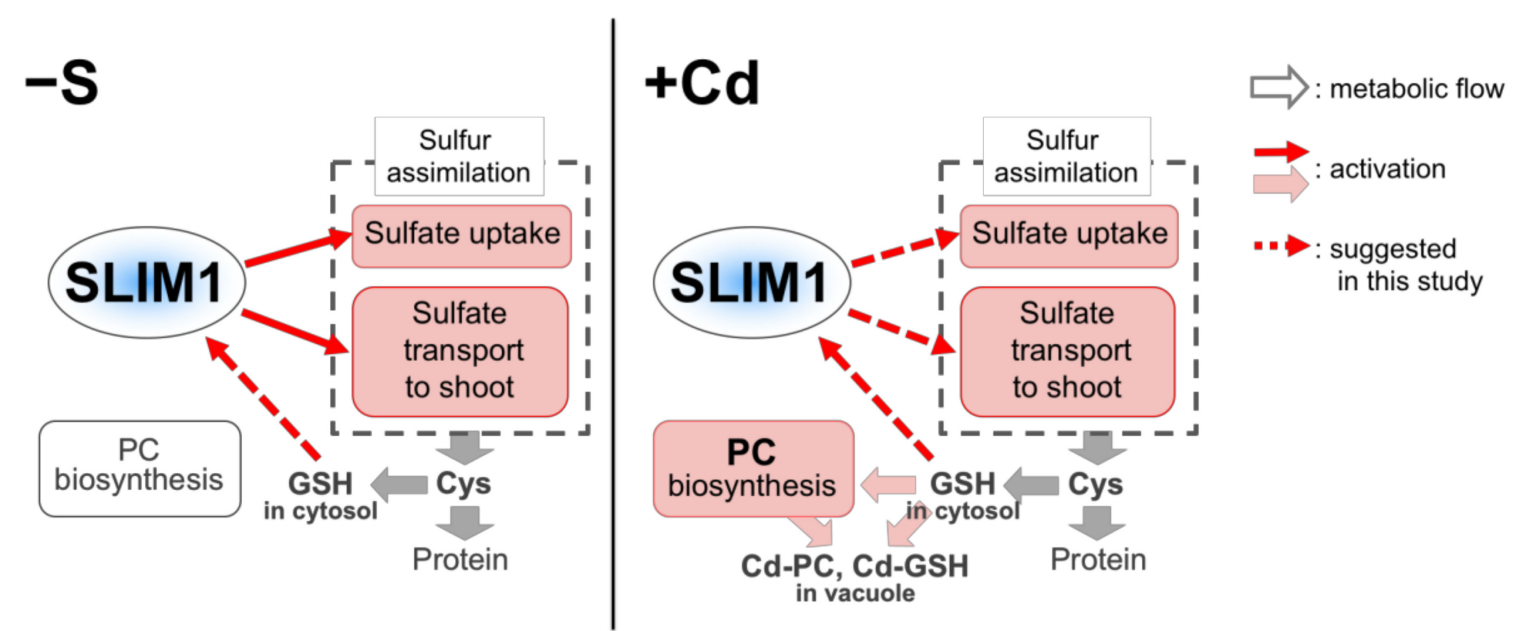

Figure 8. The role of SLIM1 in the regulation of S assimilation under $-\mathrm{S}$ and Cd treatment. Left panel: Plants increase sulfate uptake and its translocation to shoots in response to -S. SLIM1 stimulates the expression of genes involved in S assimilation, including SULTR1;2. Right panel: Cd treatment increases sulfate uptake, distribution to shoots, and PC accumulation. Shortage of cytosolic GSH can occur because of either sulfate deficiency (left panel) or the enhanced PC synthesis and the compartmentalization of Cd-PC or Cd-GSH to the vacuole (right panel). As a result, SLIM1 is activated in either scenario. Open arrow: metabolic flow; red or pink arrow: activation; dotted arrow: suggested in this study.

The slim1 mutants had a lower Cd tolerance than 1;2PGN despite of the fact that their roots accumulated less $\mathrm{Cd}$ than those of 1;2PGN (Figure 1, Figure 6c). Reduced Cd accumulation in roots associated with a less tolerant Cd phenotype was also observed in the disruption lines of SULTR1;2 [51]. In addition to this, sulfate application increased $\mathrm{Cd}$ concentrations in the roots of wheat, mustard, and buckwheat plant $[32,35,75]$. However, these findings should be considered in relation to the general suggestion that the ability of plants to accumulate higher heavy metal levels in shoots rather than in roots is associated with a higher heavy metal tolerance [8]. Further research should investigate the effect of the decreased sulfate uptake on the uptake and transport of $\mathrm{Cd}$. Examining the $\mathrm{Cd}$ transport in SULTR1;2 disruption lines and $\operatorname{sim} 1$ mutants may clarify why these plants are less tolerant to Cd.

In conclusion, we demonstrated that SLIM1 contributed to the increased sulfate uptake and PC accumulation under $\mathrm{Cd}$ exposure. Our results imply that demand-driven $-\mathrm{S}$ responses may be induced in Cd-treated plants, which are stimulated by SLIM1. However, further questions about the underlying mechanisms employed by SLIM1 for regulating these transcriptomic changes under both $-\mathrm{S}$ and $\mathrm{Cd}$ exposure remain to be clarified.

\section{Materials and Methods}

\subsection{Plant Materials and Growth Conditions}

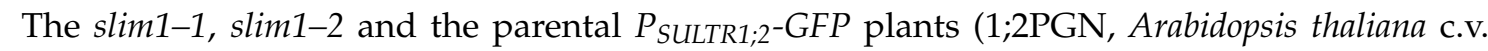
Columbia; $[53,55]$ ) were used as the plant materials. $1 ; 2 \mathrm{PGN}$ is a transgenic plant carrying a fusion gene construct that expresses GFP under the control of the 2160 bp $5^{\prime}$-upstream region of SULTR1;2, which accumulates GFP simultaneously with the increase of SULTR1;2 expression [55]. The slim1 mutants were preselected from the mutagenized $\mathrm{M}_{2}$ population of $1 ; 2 \mathrm{PGN}$ by screening for the phenotype of impaired GFP fluorescence under $-\mathrm{S}$, and were further tested for the inability to induce a 
broad range of $-\mathrm{S}$ responses, including the upregulation of sulfate uptake, glucosinolate catabolism, and the downregulation of glucosinolate synthesis [53].

The plants were vertically grown on mineral nutrient medium [76,77] containing $1500 \mu \mathrm{M} \mathrm{MgSO}_{4}$, $1 \%$ sucrose, and $0.8 \%$ agarose, at $22{ }^{\circ} \mathrm{C}$ under constant illumination $\left(40 \mu \mathrm{mol} \mathrm{m}{ }^{-2} \mathrm{~s}^{-1}\right)$ in Figure 1 , Figure 2, Figure 3, Figure 4. In Figure 5, Figure 6, Figure 7 agar medium was prepared with washed agar which was washed twice with $6 \mathrm{~L}$ of deionized water and $2 \mathrm{~L}$ of distilled water followed by the vacuum filtration. To adjust the sulfate concentration in the media, $1500 \mu \mathrm{M}$ and $15 \mu \mathrm{M} \mathrm{MgSO}_{4}$ were added, and the corresponding media were named as S1500 and S15, respectively. In S15, Mg concentration was adjusted to $1500 \mu \mathrm{M}$ by adding $\mathrm{MgCl}_{2}$. For Cd treatment, the plants were grown vertically for 10 days on the media containing 0 or $20 \mu \mathrm{M} \mathrm{CdCl}_{2}$ (cadmium chloride; Nacalai Tesque, Kyoto, Japan).

Shoot and root tissues were separately harvested, rinsed with distilled water, and used for each analysis. Cd tolerance measurements were performed as previously described [78]. The $\mathrm{Cd}$ tolerance rate $(\%)$ was calculated by dividing the fresh weights of the Cd-treated plants $(n=4)$ by the fresh weights of the control plants (Figure 1a).

\subsection{Cd Analysis}

Cd levels were analyzed using an atomic absorption photometer, as described previously [47]. Shoots and roots were dried at $70{ }^{\circ} \mathrm{C}$ for 5 days, and digested in $1 \mathrm{~mL}$ of $\mathrm{HNO}_{3}$. The $\mathrm{Cd}$ concentration of each digested solution was measured with an atomic absorption photometer (AAnalyst 200; PerkinElmer, Waltham, MA, USA), using a Cd standard solution (Kanto Chemical, Tokyo, Japan) as a reference.

\subsection{Sulfate Uptake and Translocation Activity}

The sulfate uptake rates and sulfate distribution were analyzed using $\left[{ }^{35} \mathrm{~S}\right]$ sodium sulfate (American Radiolabeled Chemicals, St. Louis, Missouri, USA) as previously described [40,63,79]. Plants were vertically grown for 10 days on the media supplemented with 0 or $20 \mu \mathrm{M} \mathrm{CdCl}_{2}$. The roots were submerged in nutrient solution containing $1 \mathrm{MBq}\left[{ }^{35} \mathrm{~S}\right]$ sodium sulfate and incubated for $60 \mathrm{~min}$. After several times of wash, radioactivity was measured using a liquid scintillation counter LSC-5100 (Hitachi-Aloka, Tokyo, Japan).

\subsection{Measurements of Sulfate, Thiols (Cys, GSH, and PCs), and Total S Levels}

Plant tissues were frozen in liquid nitrogen and ground with Tissue Lyser MM300 (Retsch, Germany), and then extracted with 5 volumes of $10 \mathrm{mM} \mathrm{HCl}$. The resultant mixtures were centrifuged at $4{ }^{\circ} \mathrm{C}, 13,000 \mathrm{rpm}$ for $15 \mathrm{~min}$. The supernatant was used for the sulfate and thiol analysis, and the precipitate was used for the total $\mathrm{S}$ analysis.

The sulfate content was determined by ion chromatography (IC-2001, TOSOH, Tokyo, Japan), as described previously $[40,63]$. The content of Cys, GSH, and PCs (PC2, PC3, and PC4) was determined using an HPLC-fluorescent detection system after labeling of thiol bases by monobromobimane as described previously [51,80]. In Figure 4, the labeled products were separated as described previously [51]. In Figure 7, the labeled products were separated using an HPLC system (JASCO) with the TSKgel ODS-120T column $(150 \times 4.6 \mathrm{~mm}$, TOSOH) and detected with a scanning fluorescence detector FP-920 (JASCO), monitoring for fluorescence of thiol-bimane adducts at $478 \mathrm{~nm}$ under excitation at $390 \mathrm{~nm}$. PC2, PC3, and PC4 (Anaspec, Germany), along with GSH and Cys (Nacalai Tesque), were used as standards. The total $\mathrm{S}$ content was determined by inductively coupled plasma mass spectroscopy (ICP-MS, Agilent7700x, Agilent Technologies, Santa Clara, CA, USA) as described previously [63].

\subsection{Quantitative Real-Time PCR ( $q R T-P C R)$}

Total RNA was extracted from shoot and root tissues using Sepasol-RNA I (Nacalai Tesque) and reverse transcription was conducted using the PrimeScript RT Reagent Kit with gDNA Eraser (Takara, 
Japan). Subsequently, qRT-PCR was conducted using SYBR Premix Ex Taq II (Takara) and a Thermal Cycler Dice Real Time System (Takara). Relative mRNA abundance was determined using the delta delta $\mathrm{Ct}(\triangle \Delta \mathrm{Ct}$ ) method and ubiquitin2 (UBQ2, accession no. J05508) was used as a constitutive internal control. Gene-specific primers for qRT-PCR were previously described [51].

\subsection{Imaging and Quantification of GFP Fluorescence}

The expression of GFP in whole intact seedlings was visualized by using the image analyzer, an Amersham Typhoon scanner 5, equipped with a 525BP20 filter and a 488-nm laser (GE Healthcare, Chicago, USA). Relative intensities of GFP fluorescence were determined by ImageQuant TL as the average intensities in the corresponding areas of root tissues.

\subsection{Statistical Analysis}

In Figure 1, Figure 2, Figure 3, Figure 4 Student's t-test (two-tailed) was used for pairwise comparisons. The Tukey-Kramer test was used for multivariate comparisons. In Figure 5, Figure 6, Figure 7 significant differences among 1;2PGN plants were analyzed for significance using the Tukey-Kramer test, and the significant differences between 1;2PGN and slim1 mutants under the same treatment were analyzed for significance using Student's $t$-test.

Author Contributions: A.M.-N. designed the research. Y.T. and A.M.-N. performed the initial experiments presented in Figure 1, Figure 2, Figure 3, Figure 4. S.K. prepared plant samples in Figures 1 and 2. S.K. and C.Y. performed the sulfate uptake assay and sulfate quantification. A.S. and C.Y. performed qRT-PCR. Y.M. analyzed S content by ICP-MS. C.Y. prepared plant samples in Figure 5,Figure 6, Figure 7 and analyzed GFP fluorescence. N.O.-O. and C.Y. analyzed thiol levels in Figures 4 and 7, respectively. C.Y. and A.M.-N. wrote the manuscript. All authors have read and agreed to the published version of the manuscript.

Funding: This research was funded by Japan Society for the Promotion of Science KAKENHI grant Number JP24380040 (for A.M.-N.), JP15KT0028 (for N.O.O.), JP17H03785 (for A.M.-N.), JP19H02859 (for N.O.-O.), and Fukui Prefectural University Regional Contribution Research Project Participated by Local Residents grant number 21-7 (for A.M.-N.).

Acknowledgments: We thank Saeko Hamano, Akiko Hayashi, and Yukiko Okuo for technical support. We thank Shin-ichi Nakamura for providing PC standards in Figure 4. The ICP-MS (Agilent7700x) analysis was performed at the Center of Advanced Instrumental Analysis, Kyushu University under the kind instruction by Prof. Midori Watanabe. Plant growth and seed harvesting were done at the Biotron Application Center, Kyushu University.

Conflicts of Interest: The authors have no conflicts of interest to declare.

\section{References}

1. Nawrot, T.; Plusquin, M.; Hogervorst, J.; Roels, H.A.; Celis, H.; Thijs, L.; Vangronsveld, J.; Van Hecke, E.; Staessen, J.A. Environmental exposure to cadmium and risk of cancer: A prospective population-based study. Lancet Oncol. 2006, 7, 119-126. [CrossRef]

2. Järup, L.; Akesson, A. Current status of cadmium as an environmental health problem. Toxicol. Appl. Pharmacol. 2009, 238, 201-208. [CrossRef] [PubMed]

3. Clemens, S.; Aarts, M.G.; Thomine, S.; Verbruggen, N. Plant science: The key to preventing slow cadmium poisoning. Trends Plant Sci. 2013, 18, 92-99. [CrossRef] [PubMed]

4. Thomine, S.; Wang, R.; Ward, J.M.; Crawford, N.M.; Schroeder, J.I. Cadmium and iron transport by members of a plant metal transporter family in Arabidopsis with homology to Nramp genes. Proc. Natl. Acad. Sci. USA 2000, 97, 4991-4996. [CrossRef] [PubMed]

5. Clemens, S.; Ma, J.F. Toxic Heavy Metal and Metalloid Accumulation in Crop Plants and Foods. Annu. Rev. Plant Biol. 2016, 29, 489-512. [CrossRef] [PubMed]

6. Takahashi, R.; Bashir, K.; Ishimaru, Y.; Nishizawa, N.K.; Nakanishi, H. The role of heavy-metal ATPases, HMAs, in zinc and cadmium transport in rice. Plant Signal. Behav. 2012, 7, 1605-1607. [CrossRef]

7. Yoneyama, T.; Ishikawa, S.; Fujimaki, S. Route and Regulation of Zinc, Cadmium, and Iron Transport in Rice Plants (Oryza sativa L.) during Vegetative Growth and Grain Filling: Metal Transporters, Metal Speciation, Grain Cd Reduction and Zn and Fe Biofortification. Int. J. Mol. Sci 2015, 16, 19111-19129. [CrossRef] 
8. Lin, Y.F.; Aarts, M.G. The molecular mechanism of zinc and cadmium stress response in plants. Cell Mol. Life Sci. 2012, 69, 3187-3206. [CrossRef]

9. Choppala, G.; Saifullah Bolan, N.; Bibi, S.; Iqbal, M.Z.; Rengel, Z.; Kunhikrishnan, A.; Ashwath, N.; Sik Ok, Y. Cellular mechanisms in higher plants governing tolerance to cadmium toxicity. Crit. Rev. Plant Sci. 2014, 33, 374-391. [CrossRef]

10. Clemens, S. Toxic metal accumulation, responses to exposure and mechanisms of tolerance in plants. Biochimie 2006, 88, 1707-1719. [CrossRef]

11. Verbruggen, N.; Hermans, C.; Schat, H. Mechanisms to cope with arsenic or cadmium excess in plants. Curr. Opin. Plant Biol. 2009, 12, 364-372. [CrossRef] [PubMed]

12. Yadav, S.K. Heavy metals toxicity in plants: An overview on the role of glutathione and phytochelatins in heavy metal stress tolerance of plants. South African J. Bot. 2010, 76, 167-179. [CrossRef]

13. Chmielowska-Bak, J.; Gzyl, J.; Rucińska-Sobkowiak, R.; Arasimowicz-Jelonek, M.; Deckert, J. The new insights into cadmium sensing. Front. Plant Sci. 2014, 5, 245. [CrossRef] [PubMed]

14. Cobbett, C.S. Phytochelatins and their roles in heavy metal detoxification. Plant Physiol. 2000, 123, 825-832. [CrossRef]

15. Cobbett, C.S.; May, M.J.; Howden, R.; Rolls, B. The glutathione-deficient, cadmium-sensitive mutant, cad2-1, of Arabidopsis thaliana is deficient in gamma-glutamylcysteine synthetase. Plant J. 2002, 16, 73-78. [CrossRef]

16. Seth, C.S.; Remans, T.; Keunen, E.; Jozefczak, M.; Gielen, H.; Opdenakker, K.; Weyens, N.; Vangronsveld, J.; Cuypers, A. Phytoextraction of toxic metals: A central role for glutathione. Plant Cell Environ. 2012, 35, 334-346. [CrossRef]

17. Salt, D.E.; Rauser, W.E. MgATP-Dependent Transport of Phytochelatins Across the Tonoplast of Oat Roots. Plant Physiol. 1995, 107, 1293-1301. [CrossRef]

18. Lu, S.C. Glutathione Synthesis. Biochim. Biophys. Acta. 2013, 1830, 3143-3153. [CrossRef]

19. Cobbett, C.; Goldsbrough, P. Phytochelatins and metallothioneins: Roles in heavy metal detoxification and homeostasis. Annu. Rev. Plant Biol. 2002, 53, 159-182. [CrossRef]

20. Vatamaniuk, O.K.; Mari, S.; Lu, Y.P.; Rea, P.A. Mechanism of heavy metal ion activation of phytochelatin (PC) synthase: Blocked thiols are sufficient for PC synthase-catalyzed transpeptidation of glutathione and related thiol peptides. J. Biol. Chem. 2000, 275, 31451-31459. [CrossRef]

21. Herbette, S.; Taconnat, L.; Hugouvieux, V.; Piette, L.; Magniette, M.L.; Cuine, S.P.; Auroy, P.; Richaud, P.; Forestier, C.; Bourguignon, J.; et al. Genome-wide transcriptome profiling of the early cadmium response of Arabidopsis roots and shoots. Biochimie 2006, 88, 1751-1765. [CrossRef] [PubMed]

22. Zenk, M.H. Heavy metal detoxification in higher plants-a review. Gene 1996, 179, 21-30. [CrossRef]

23. Vestergaard, M.; Matsumoto, S.; Nishikori, S.; Shiraki, K.; Hirata, K.; Takagi, M. Chelation of cadmium ions by phytochelatin synthase: Role of the cysteine-rich C-terminal. Anal. Sci. 2008, 24, 277-281. [CrossRef] [PubMed]

24. Howden, R.; Goldsbrough, P.B.; Andersen, C.R.; Cobbett, C.S. Cadmium-sensitive, cad1 mutants of Arabidopsis thaliana are phytochelatin deficient. Plant Physiol. 1995, 107, 1059-1066. [CrossRef]

25. Cobbett, C.S.; May, M.J.; Howden, R.; Rolls, B. The glutathione-deficient, cadmium- sensitive mutant, cad2-1, of Arabidopsis thaliana is deficient in gamma- glutamylcysteine synthetase. Plant J. 1998, 16, 73-78. [CrossRef]

26. Ha, S.B.; Smith, A.P.; Howden, R.; Dietrich, W.M.; Bugg, S.; O'Connell, M.J.; Goldsbrough, P.B.; Cobbett, C.S. Phytochelatin synthase genes from Arabidopsis and the yeast Schizosaccharomyces pombe. Plant Cell 1999, 11, 1153-1163. [CrossRef]

27. Leustek, T. Sulfate metabolism. Arabidopsis Book 2002, 1, e0017. [CrossRef]

28. Saito, K. Sulfur assimilatory metabolism. The long and smelling road. Plant Physiol. 2004, 136, $2443-2450$. [CrossRef]

29. Takahashi, H.; Kopriva, S.; Giordano, M.; Saito, K.; Hell, R. Sulfur assimilation in photosynthetic organisms: Molecular functions and regulations of transporters and assimilatory enzymes. Annu. Rev. Plant Biol. 2011, 62, 157-184. [CrossRef]

30. Long, S.R.; Kahn, M.; Seefeldt, L.; Tsay, Y.F.; Kopriva, S. Chapter 16 nitrogen and sulfur. In Biochemistry E Molecular Biology of Plants; Buchanan, B.B., Gruissem, W., Jones, R.L., Eds.; Wiley Blackwell: Hoboken, NJ, USA, 2015; pp. 746-768.

31. Davidian, J.C.; Kopriva, S. Regulation of sulfate uptake and assimilation-the same or not the same? Mol. Plant 2010, 3, 314-325. [CrossRef] 
32. Lu, Y.; Wang, Q.F.; Li, J.; Xiong, J.; Zhou, L.N.; He, S.L.; Zhang, J.Q.; Chen, Z.A.; He, S.G.; Liu, H. Effects of exogenous sulfur on alleviating cadmium stress in tartary buckwheat. Sci. Rep. 2019, 9, 7397. [CrossRef] [PubMed]

33. Lou, L.; Kang, J.; Pang, H.; Li, Q.; Du, X.; Wu, W.; Chen, J.; Lv, J. Sulfur Protects Pakchoi (Brassica chinensis L.) Seedlings against Cadmium Stress by Regulating Ascorbate-Glutathione Metabolism. Int. J. Mol. Sci. 2017, 18, 1628. [CrossRef] [PubMed]

34. Khan, N.A.; Asgher, M.; Per, T.S.; Masood, A.; Fatma, M.; Khan, M.I. Ethylene Potentiates Sulfur-Mediated Reversal of Cadmium Inhibited Photosynthetic Responses in Mustard. Front. Plant Sci. 2016, 7, 1628. [CrossRef] [PubMed]

35. Matraszek, R.; Hawrylak-Nowak, B.; Chwil, S.; Chwil, M. Interaction Between Cadmium Stress and Sulphur Nutrition Level on Macronutrient Status of Sinapis alba L. Water Air Soil Pollut. 2016, 227, 355. [CrossRef]

36. Zaid, A.; Bhat, J.A.; Wani, S.H.; Masoodi, K.Z. Role of Nitrogen and Sulfur in Mitigating Cadmium induced Metabolism Alterations in Plants. J. Plant Res. 2019, 35, 121-141. [CrossRef]

37. Takahashi, H.; Watanabe-Takahashi, A.; Smith, F.W.; Blake-Kalff, M.; Hawkesford, M.J.; Saito, K. The role of three functional sulfate transporters involved in uptake and translocation of sulfate in Arabidopsis thaliana. Plant J. 2000, 23, 171-182. [CrossRef]

38. Kataoka, T.; Hayashi, N.; Yamaya, T.; Takahashi, H. Root-to-shoot transport of sulfate in Arabidopsis: Evidence for the role of SULTR3;5 as a component of low-affinity sulfate transport system in the root vasculature. Plant Physiol. 2004, 136, 4198-4204. [CrossRef]

39. Maruyama-Nakashita, A.; Watanabe-Takahashi, A.; Inoue, E.; Yamaya, T.; Saito, K.; Takahashi, H. Sulfur-responsive elements in the $3^{\prime}$-nontranscribed intergenic region are essential for the induction of SULFATE TRANSPORTER 2;1 gene expression in Arabidopsis roots under sulfur deficiency. Plant Cell 2015, 27, 1279-1296. [CrossRef]

40. Cao, M.J.; Wang, Z.; Wirtz, M.; Hell, R.; Oliver, D.J.; Xiang, C.B. SULTR3;1 is a chloroplast- localized sulfate transporter in Arabidopsis thaliana. Plant J. 2013, 73, 607-616. [CrossRef]

41. Zuber, H.; Davidian, J.C.; Aubert, G.; Aime, D.; Belghazi, M.; Lugan, R.; Heintz, D.; Wirtz, M.; Hell, R.; Thompson, R.; et al. The seed composition of Arabidopsis mutants for the group 3 sulfate transporters indicates a role in sulfate translocation within developing seeds. Plant Physiol. 2010, 154, 913-926. [CrossRef]

42. Maruyama-Nakashita, A.; Ohkama-Ohtsu, N. Chapter 13 Sulfur Assimilation and Glutathione Metabolism in Plants. In Glutathione in Plant Growth, Development, and Stress Tolerance; Hossain, M.A., Mostofa, M.G., Diaz-Vivancos, P., Burritt, D.J., Fujita, M., Tran, L.-S.P., Eds.; Springer International Publishing: Basel, Switzerland, 2017; pp. 287-308.

43. Kataoka, T.; Watanabe-Takahashi, A.; Hayashi, N.; Ohnishi, M.; Mimura, T.; Buchner, P.; Hawkesford, M.J.; Yamaya, T.; Takahashi, H. Vacuolar sulfate transporters are essential determinants controlling internal distribution of sulfate in Arabidopsis. Plant Cell 2004, 16, 2693-2704. [CrossRef] [PubMed]

44. Xiang, C.; Oliver, D.J. Glutathione metabolic genes coordinately respond to heavy metals and jasmonic acid in Arabidopsis. Plant Cell 1998, 10, 1539-1550. [CrossRef] [PubMed]

45. Harada, E.; Yamaguchi, Y.; Koizumi, N.; Sano, H. Cadmium stress induces production of thiol compounds and transcripts for enzymes in involved in sulfur assimilation pathways in Arabidopsis. J. Plant Physiol. 2002, 159, 445-448. [CrossRef]

46. Nocito, F.F.; Pirovano, L.; Cocucci, M.; Sacchi, G.A. Cadmium-induced sulfate uptake in maize roots. Plant Physiol. 2002, 129, 1872-1879. [CrossRef]

47. Nocito, F.F.; Lancilli, C.; Crema, B.; Fourcroy, P.; Davidian, J.C.; Sacchi, G.A. Heavy metal stress and sulfate uptake in maize roots. Plant Physiol. 2006, 141, 1138-1148. [CrossRef]

48. Xiao, Y.; Du, Z.; Qi, X.; Wu, H.; Guo, W.; Zhao, Z. RNA-sequencing analysis reveals transcriptional changes in the roots of low-cadmium-accumulating winter wheat under cadmium stress. Acta Physiol. Plant. 2019, 41, 13. [CrossRef]

49. Rouached, H.; Wirtz, M.; Alary, R.; Hell, R.; Arpat, A.B.; Davidian, J.C.; Fourcroy, P.; Berthomieu, P. Differential regulation of the expression of two high-affinity sulfate transporters, SULTR1.1 and SULTR1.2, in Arabidopsis. Plant Physiol. 2008, 147, 897-911. [CrossRef]

50. Shibagaki, N.; Rose, A.; McDermott, J.P.; Fujiwara, T.; Hayashi, H.; Yoneyama, T.; Davies, J.P. Selenate-resistant mutants of Arabidopsis thaliana identify Sultr1;2, a sulfate transporter required for efficient transport of sulfate into roots. Plant J. 2002, 29, 475-486. [CrossRef] 
51. Yamaguchi, C.; Takimoto, Y.; Ohkama-Ohtsu, N.; Hokura, A.; Shinano, T.; Nakamura, T.; Suyama, A.; Maruyama-Nakashita, A. Effects of cadmium treatment on the uptake and translocation of sulfate in Arab. Thaliana. Plant Cell Physiol. 2016, 57, 2353-2366. [CrossRef]

52. Maruyama-Nakashita, A.; Inoue, E.; Watanabe-Takahashi, A.; Yamaya, T.; Takahashi, H. Transcriptome profiling of sulfur-responsive genes in Arabidopsis reveals global effect on sulfur nutrition on multiple metabolic pathways. Plant Physiol. 2003, 132, 597-605. [CrossRef]

53. Maruyama-Nakashita, A.; Nakamura, Y.; Tohge, T.; Saito, K.; Takahashi, H. Arabidopsis SLIM1 is a central transcriptional regulator of plant sulfur response and metabolism. Plant Cell 2006, 18, 3235-3251. [CrossRef]

54. Besson-Bard, A.; Gravot, A.; Richaud, P.; Auroy, P.; Duc, C.; Gaymard, F.; Taconnat, L.; Renou, J.P.; Pugin, A.; Wendehenne, D. Nitric oxide contributes to cadmium toxicity in Arabidopsis by promoting cadmium accumulation in roots and by up-regulating genes related to iron uptake. Plant Physiol. 2009, 149, 1302-1315. [CrossRef] [PubMed]

55. Maruyama-Nakashita, A.; Nakamura, Y.; Yamaya, T.; Takahashi, H. A novel regulatory pathway of sulfate uptake in Arabidopsis roots: Implication of CRE1/WOL/AHK4-mediated cytokinin-dependent regulation. Plant J. 2004, 38, 779-789. [CrossRef] [PubMed]

56. Kawashima, C.G.; Yoshimoto, N.; Maruyama-Nakashita, A.; Tsuchiya, Y.N.; Saito, K.; Takahashi, H.; Dalmay, T. Sulphur starvation induces the expression of microRNA-395 and one of its target genes but in different cell types. Plant J. 2009, 57, 313-321. [CrossRef] [PubMed]

57. Lancilli, C.; Giacomini, B.; Lucchini, G.; Davidian, J.C.; Cocucci, M.; Sacchi, G.A.; Nocito, F.F. Cadmium exposure and sulfate limitation reveal differences in the transcriptional control of three sulfate transporter (Sultr1;2) genes in Brassica juncea. BMC Plant Biol. 2014, 14, 132. [CrossRef]

58. Yamaguchi, C.; Maruyama-Nakashita, A. Sulfate Transporters Involved in Cd-Induced Changes of Sulfate Uptake and Distribution in Arabidopsis thaliana. In Sulfur Metabolism in Higher Plants-Fundamental. Environmental and Agricultural Aspects; De Kok, L.J., Hawkesford, M.J., Haneklaus, S.H., Schnug, E., Eds.; Springer: Cham, Switzerland, 2017; pp. 199-205.

59. Takahashi, H.; Yamazaki, M.; Sasakura, N.; Watanabe, A.; Leustek, T.; Engler, J.A.; Engler, G.; Van Montagu, M.; Saito, K. Regulation of sulfur assimilation in higher plants: A sulfate transporter induced in sulfate starved roots plays a central role in Arabidopsis thaliana. Proc. Natl. Acad. Sci. USA 1997, 94, 11102-11107. [CrossRef]

60. Vidmar, J.J.; Tagmount, A.; Cathala, N.; Touraine, B.; Davidian, J.E. Cloning and characterization of a root specific high-affinity sulfate transporter from Arabidopsis thaliana. Febs Lett. 2000, 475, 65-69. [CrossRef]

61. Yoshimoto, N.; Takahashi, H.; Smith, F.W.; Yamaya, T.; Saito, K. Two distinct high-affinity sulfate transporters with different inducibilities mediate uptake of sulfate in Arabidopsis roots. Plant J. 2002, 29, 465-473. [CrossRef]

62. Yoshimoto, N.; Inoue, E.; Watanabe-Takahashi, A.; Saito, K.; Takahashi, H. Posttranscriptional regulation of high-affinity sulfate transporters in Arabidopsis by sulfur nutrition. Plant Physiol. 2007, 145, 378-388. [CrossRef]

63. Kimura, Y.; Ushiwatari, T.; Suyama, A.; Tominaga-Wada, R.; Wada, T.; Maruyama-Nakashita, A. Contribution of root hair development to sulfate uptake in Arabidopsis. Plants 2019, 8, 106. [CrossRef]

64. Liu, X.; Wu, F.H.; Li, J.X.; Chen, J.; Wang, G.H.; Wang, W.H.; Hu, W.J.; Gao, L.J.; Wang, Z.L.; Chen, J.H.; et al. Glutathione homeostasis and Cd tolerance in the Arabidopsis sultr1;1-sultr1;2 double mutant with limiting sulfate supply. Plant Cell Rep. 2016, 35, 397-413. [CrossRef] [PubMed]

65. Maruyama-Nakashita, A. Metabolic changes sustain the plant life in low-sulfur environments. Curr. Opin. Plant Biol. 2017, 39, 144-151. [CrossRef] [PubMed]

66. Crawford, M.N.; Kahn, L.M.; Leustek, T.; Long, R.S. Chapter 16 Nitrogen and Sulfur. In Biochemistry and Molecular Biology of Plants; Buchanan, B.B., Wilhelm, G., Jones, R.L., Eds.; American Society of Plant Physiologists: Rockville, MD, USA, 2000; pp. 658-710.

67. Park, J.; Song, W.Y.; Ko, D.; Eom, Y.; Hansen, T.H.; Schiller, M.; Lee, T.G.; Martinoia, E.; Lee, Y. The phytochelatin transporters AtABCC1 and AtABCC2 mediate tolerance to cadmium and mercury. Plant J. 2012, 69, 278-288. [CrossRef]

68. Maruyama-Nakashita, A.; Nakamura, Y.; Yamaya, T.; Takahashi, H. Regulation of high-affinity sulphate transporters in plants: Towards systematic analysis of sulphur signalling and regulation. J. Exp. Bot. 2004, 55, 1843-1849. [CrossRef] [PubMed] 
69. Zhang, B.; Pasini, R.; Dan, H.; Joshi, N.; Zhao, Y.; Leustek, T.; Zheng, Z.L. Aberrant gene expression in the Arabidopsis SULTR1;2 mutants suggests a possible regulatory role for this sulfate transporter in response to sulfur nutrient status. Plant J. 2014, 77, 185-197. [CrossRef] [PubMed]

70. Zheng, Z.L.; Zhang, B.; Leustek, T. Transceptors at the boundary of nutrient transporters and receptors: A new role for Arabidopsis SULTR1;2 in sulfur sensing. Front. Plant Sci. 2014, 11, 710. [CrossRef] [PubMed]

71. Hirai, M.Y.; Fujiwara, T.; Awazuhara, M.; Kimura, T.; Noji, M.; Saito, K. Global expression profiling of sulfur-starved Arabidopsis by DNA macroarray reveals the role of $O$-acetyl-l-serine as a general regulator of gene expression in response to sulfur nutrition. Plant J. 2003, 33, 651-663. [CrossRef]

72. Hopkins, L.; Parmar, S.; Błaszczyk, A.; Hesse, H.; Hoefgen, R.; Hawkesford, M.J. O-Acetylserine and the regulation of expression of genes encoding components for sulfate uptake and assimilation in potato. Plant Physiol. 2005, 138, 433-440. [CrossRef]

73. Hubberten, H.M.; Klie, S.; Caldana, C.; Degenkolbe, T.; Willmitzer, L.; Hoefgen, R. Additional role of $\mathrm{O}$-acetylserine as a sulfur status-independent regulator during plant growth. Plant J. 2012, 70, 666-677. [CrossRef]

74. Dong, Y.; Silbermann, M.; Speiser, A.; Forieri, I.; Linster, E.; Poschet, G.; Allboje Samami, A.; Wanatabe, M.; Sticht, C.; Teleman, A.A.; et al. Sulfur availability regulates plant growth via glucose-TOR signaling. Nat. Commun. 2017, 27, 1174. [CrossRef]

75. Shi, G.; Lu, H.; Liu, H.; Lou, L.; Zhang, P.; Song, G.; Zhou, H.; Ma, H. Sulfate application decreases translocation of arsenic and cadmium within wheat (Triticum aestivum L.) plant. Sci. Total Environ. 2020, 713, 136665. [CrossRef] [PubMed]

76. Fujiwara, T.; Hirai, M.Y.; Chino, M.; Komeda, Y.; Naito, S. Effects of sulfur nutrition on expression of the soybean seed storage protein genes in transgenic petunia. Plant Physiol. 1992, 99, 263-268. [CrossRef] [PubMed]

77. Hirai, M.Y.; Fujiwara, T.; Chino, M.; Naito, S. Effects of sulfate concentrations on the expression of a soybean seed storage protein gene and its reversibility in transgenic Arabidopsis thaliana. Plant Cell Physiol. 1995, 36, 1331-1339. [CrossRef] [PubMed]

78. Bahmani, R.; Modareszadeh, M.; Kim, D.; Hwang, S. Overexpression of tobacco UBQ2 increases Cd tolerance by decreasing $\mathrm{Cd}$ accumulation and oxidative stress in tobacco and Arabidopsis. Environ. Exp. Bot. 2019, 166, 103805. [CrossRef]

79. Yoshimoto, N.; Kataoka, T.; Maruyama-Nakashita, A.; Takahashi, H. Measurement of uptake and root-to-shoot distribution of sulfate in Arabidopsis seedlings. Bio-Protocol 2016, 6, e1700. [CrossRef]

80. Minocha, R.; Thangavel, P.; Dhankher, O.P.; Long, S. Separation and quantification of monothiols and phytochelatins from a wide variety of cell cultures and tissues of trees and other plants using high performance liquid chromatography. J. Chromatogr. A 2008, 1207, 72-83. [CrossRef] 